\title{
LA DIMENSIÓN INTELECTUAL EN LA NUEVA «RATIO FUNDAMENTALIS INSTITUTIONIS SACERDOTALIS»
}

DOI: https://doi.org/10.52039/seminarios.v63i221.61

ANTONIO DIEgo HERNÁNDEZ*

El pasado 8 de diciembre de 2016 se presentaba en Roma la nueva edición de las Normas fundamentales para la formación sacerdotal, el documento que regula y orienta las claves formativas para los aspirantes al sacerdocio en la Iglesia Católica. La nueva Ratio, como se conoce popularmente, venía a sustituir al anterior documento publicado en 1985 por la Congregación para la Educación Católica, hasta ese momento responsable de los seminarios y otras casas de formación para jóvenes aspirantes al sacerdocio.

En treinta años el mundo ha dado un cambio vertiginoso, ante el cual la formación sacerdotal no puede permanecer ajena. La irrupción de los medios de comunicación, por ejemplo, ha dado un vuelco drástico a la forma en que nos conectamos con el resto del mundo y entre nosotros. Las redes sociales, que hoy son el pan nuestro de cada día, configuran también una nueva forma de comprender la sociedad y de acercarnos a aquellos que antes eran más lejanos. Los seminarios de los años 80 o 90 ya no se corresponden con las comunidades actuales de formación, porque los candidatos tienen un perfil distinto que entraña unos valores y unas lagunas también nuevas ${ }^{1}$. Sin embargo, el propósito sigue siendo el mismo: formar pastores según el corazón de Dios.

No cabe duda que el documento que más ha influido en la configuración formativa de estas últimas décadas ha sido Pastores dabo vobis, de Juan Pablo II. Significó hace 25 años un hito en la comprensión de las distintas dimensiones de las que debía ocuparse el quehacer formativo, pero otorgándoles una consideración tal que entre todas se formara una unidad.

* Sacerdote operario. Profesor y formador del Seminario de Santa Rosa de Lima, Caracas (Venezuela).

1. Remitimos aquí al artículo publicado por Lorenzo Trujillo, ¿Los nuevos seminaristas?: Seminarios 167 (2003) 13-30. 
Esto no es extraño si consideramos que el hombre es uno, y que frente a la tentación de fragmentación, el pastor unifica en su ser y en su hacer todas las dimensiones de su persona de manera cohesionada.

Si nos extendemos en estas consideraciones previas es porque la nueva Ratio insiste en esta visión englobante de la formación. Quiere responder a una tentación cómoda: escorar la tarea formativa a la simple superación de materias académicas, lo cual sería no solamente contrario al espíritu formativo, sino profundamente ineficaz para la labor que luego desarrollarán los sacerdotes en la misión eclesial.

El aspecto que nos interesa desarrollar está en el título: La dimensión intelectual. Aunque sólo sea a modo orientativo, la dimensión que ha de trabajarse en la formación es la intelectual, y no solamente la «académica». Detengámonos un momento aquí: hablar de dimensión académica nos remite, en primera instancia, a un corpus de materias que han de ser abordadas de manera científica. No cabe duda de que el área académica es una parte importante de la formación de los candidatos, pero es también insuficiente si no está cobijada bajo el paraguas de la dimensión intelectual, que no se circunscribe únicamente a las asignaturas establecidas en el plan de estudios. Al respecto, nos dice la nueva Ratio:

Lejos de ser relegada al ámbito de los conocimientos o de ser entendida sólo como instrumento para recibir más informaciones sobre las distintas disciplinas, la dimensión intelectual acompaña a los presbíteros para que se dispongan a una escucha profunda de la Palabra, y también de la comunidad eclesial, para aprender a escrutar los signos de los tiempos (Ratio 117, 2).

En efecto, el fin que se persigue con la dimensión intelectual es abrir el conocimiento y el corazón al permanente desafío que plantea Dios a nuestro tiempo y también al permanente desafío que plantea el hombre de hoy a la fe. Prepararse para afrontar ambas cuestiones no significa únicamente cumplir con un «pensum» académico, por otra parte absolutamente necesario, sino fundamentalmente equiparse con las herramientas que brindan el saber filosófico y el teológico para abordar la cuestión del mundo, del hombre y de Dios. Un mundo, un hombre y un Dios que se han encontrado de manera definitiva en Cristo. ¿Acaso habremos de presentar una cosa distinta de Cristo? ¿No es Cristo, y Cristo crucificado, el que predicamos? (1 Cor 1, 23).

Con estas bases, trataremos de abordar lo que la nueva Ratio aporta al aspecto intelectual de la formación. Lo haremos en tres apartados, el primero de ellos dedicado a los números 116-118, correspondientes al capítulo $\mathrm{V}$, acerca a las dimensiones de la formación; el segundo y el tercero 
los circunscribiremos a los estudios de filosofía y de teología, respectivamente, encuadrados en el capítulo VII, que trata sobre la organización de los estudios.

\section{LA DIMENSIÓN INTELECTUAL EN EL MARCO DE LAS DIMENSIONES FORMATIVAS}

El capítulo $V$ se abre con un aspecto previo que nos parece de especial importancia, tal como queremos tratar nuestro tema: la integración de las dimensiones formativas. Puesto que hemos afirmado más arriba que la dimensión académica no es suficiente si no se integra en una dimensión intelectual, ahora hemos de atender al corolario de tal afirmación: la dimensión intelectual no resultaría eficaz si no se integrara en un plan formativo integral. La razón ya la hemos apuntado: el proceso formativo tiene como objetivo formar pastores según el corazón de Dios, lo que implica todas las facultades del hombre que ha recibido el don de la vocación presbiteral.

Es comprensible entonces que la dimensión intelectual se presente como «aquella que ofrece los instrumentos racionales necesarios para comprender los valores propios del ser pastor, procurar encarnarlos en la vida y transmitir el contenido de la fe de forma adecuada» (Ratio 89, 4). Desvincular el cultivo intelectual del aspirante al sacerdocio de la propia vida produce una «ficción» de conocimiento, pues no hay conocimiento de Dios verdadero que no tenga repercusión en su corazón. Forjar un hombre de Dios precisa, obviamente, de un conocimiento cada vez mayor de Dios mismo. Pero tal inteligencia conlleva, necesariamente, la lógica transformación de aquél que conoce, según la voluntad del que es conocido. Al respecto, la Comisión Teológica Internacional nos indicaba hace unos años: «Llevados por el Espíritu y utilizando todos los recursos de su intelecto, se esfuerzan en asimilar el contenido inteligible de la Palabra de Dios de forma que esta puede convertirse en luz y alimento para su fe $»^{2}$.

Al final de su periodo formativo en el seminario, el seminarista escuchará, mientras recibe el libro de los Evangelios, unas palabras clarificadoras que deberían estar presentes a lo largo de toda su vida de fe, especialmente en su camino formativo y específicamente en su tiempo de estudio: «Cree lo que lees, enseña lo que crees y practica lo que enseñas» ${ }^{3}$. Esta es, de fondo, la convicción que anima cualquier esfuerzo intelectual por adentrarse en los misterios sagrados.

2. Comisión Teológica Internacional, La teología hoy: perspectivas, principios y criterios, Roma 2011, 17.

3. Ritual de Ordenación de diáconos. 
Apunta algo más la Ratio que conviene que traigamos a nuestra exposición: todo el trabajo formativo se desarrolla en un clima comunitario, como expresión de la íntima fraternidad presbiteral que los pastores están llamados a vivir en el ejercicio de su misión. No es esta una cuestión menor desde el punto de vista de la dimensión intelectual, ya que una comunidad que favorece el estudio y la reflexión acerca de la verdad revelada es síntoma inequívoco de la madurez de sus miembros, que saben propiciar una cultura del debate y de la búsqueda común de los principios que informan nuestra fe, de modo que sea presentada al pueblo de Dios en su belleza y esplendor.

De manera casi mecánica hemos recorrido tres ejes configuradores de la Ratio, que indica que la formación pretende tener cuatro aspectos transversales: única, integral, comunitaria y misionera. Dado que los tres primeros ya han sido abordados de manera sucinta, dediquemos unas líneas al cuarto: el eje misionero. Mucho se ha aportado en los últimos cuarenta años acerca de la dimensión misionera de la Iglesia, especialmente a partir de la exhortación de Pablo VI Evangelii nuntiandi. Ya se hablaba allí de la importancia de la teología en los planes de evangelización:

Doctores, ya seáis teólogos o exegetas o historiadores: la obra de la evangelización tiene necesidad de vuestra infatigable labor de investigación y también de vuestra atención y delicadeza en la transmisión de la verdad, a la que vuestros estudios os acercan, pero que siempre desborda el corazón del hombre porque es la verdad misma de Dios.

Dar a la dimensión intelectual una visión misionera invita a configurar todo el trabajo de este área con una auténtica vocación de extensión del Evangelio del Reino, puesto que los pastores han de llevar la palabra de salvación a todas las gentes. Esto implica no solamente lo que conocemos como misión ad gentes, sino que también reclama una sólida preparación misionera para la nueva evangelización, tan necesaria en el contexto actual de una sociedad descristianizada.

Asentados estos aspectos acerca de la integración de las distintas dimensiones, la Ratio desarrolla en tres puntos la dimensión intelectual ( $\mathrm{n}$. 116-118). En el primero de ellos aborda la preparación que los estudios aportan a los aspirantes al sacerdocio para cumplir la misión que la Iglesia les encomendará. Tal misión encuentra su apoyo en la filosofía y en la teología, pero también en la cultura más amplia, de tal forma que el sacerdote sea capaz de anunciar al mundo el mensaje de Cristo, siendo capaz de entrar en diálogo con la sociedad y mostrando en todo momento la verdad de la fe. El P. Timothy Radcliffe, que fue Maestro general de los Dominicos, indica que la predicación es una flecha que ha de llegar al corazón del hombre, pero 
que es el estudio lo que hace que el arco se tense, de modo que la flecha pueda tomar el suficiente impulso.

El número 117 vincula la formación intelectual con el resto de dimensiones formativas. Dice de ella que se encuentra al servicio del ministerio pastoral (dimensión a la que se aboca) y encuentra alimento en la dimensión humana y espiritual (dimensiones en las que se arraiga). Con tal consideración se inserta la formación intelectual en la reflexión acerca de los saberes propios del ámbito académico, pero también se proyectan hacia el «hacer» ministerial, el ejercicio del pastoreo que habrá de llevar adelante cada presbítero. La tentación academicista de la dimensión intelectual queda corregida con una correcta orientación hacia el servicio que se presenta como meta de la formación inicial desarrollada en el Seminario.

La «forma mentis» que el aspirante habrá de adquirir tiene un medio privilegiado: el estudio profundo y orgánico de la filosofía y de la teología (Ratio 118, 7). La institución formativa se encargará de otorgar a los estudios una organización coherente y apropiada para que las distintas ramas del saber puedan ser abordadas con provecho. Mas es tarea de cada estudiante el profundizar con pasión en los estudios, de tal forma que el aprendizaje proporcionado por la casa de formación sea luego fuente de iniciativas pastorales al servicio de la evangelización. Para ello es necesario que los estudios y todos los aspectos intelectuales se vean enriquecidos con los aportes que cada nación haga a través de los planes específicos, aunando en ellos lo propuesto para la Iglesia universal con lo propio de la Iglesia particular. La «forma mentis» que se pretende conseguir en la formación intelectual no es en modo alguno un ente desvinculado de la realidad, sino un andamiaje intelectual encarnado en la realidad concreta a la que se ha de servir ministerialmente.

\section{LOS ESTUDIOS DE FILOSOFÍA}

El segundo apartado hemos querido dedicarlo a los estudios de filosofía, prescindiendo, por razón de brevedad, del apartado que la Ratio ofrece a los estudios en la etapa propedéutica y que tienen que ver con un primer acercamiento a los fundamentos de la fe y a la nivelación necesaria para afrontar los estudios posteriores (Ratio 155-157).

Al comienzo de este apartado, que ocupa los números 158-164 de la Ratio, se menciona la necesidad del estudio filosófico para llegar «a un conocimiento y a una interpretación más profundos de la persona, de su libertad, de sus relaciones con el mundo y con Dios». Luego el documento pasa a reseñar las materias que han de cursarse y que han de ser vistas siempre desde la óptica que hemos planteado. 
Muchos de los alumnos se preguntan acerca de la necesidad de estudiar filosofía, cuando ellos lo que quieren es ser sacerdotes. Pareciera como si antes de llegar a los estudios propiamente «sacerdotales» hubiera que enredarse en un galimatías de filósofos y disquisiciones sin el menor sentido para aquel que espera sumergirse en los misterios del Reino, de la fe, en las Sagradas Escrituras... Muchos incluso se desaniman en estos años de investigación en las ciencias humanas y en la historia del pensamiento. De esta manera, mientras los autores antiguos o contemporáneos se entremezclan con los tratados de lógica, metafísica o sociología, el espíritu del estudiante va languideciendo hasta tener muchas veces no un deseo místico de la fuga mundi, sino de la fuga clasis.

Y sin embargo, nada más interesante que comenzar el acercamiento a Dios con un acercamiento al hombre, pues es más fácil acceder a la mente divina si hemos aprendido cómo funciona la mente humana. Al respecto, la encíclica Fides et ratio de Juan Pablo II nos presenta distintas razones para comprender mejor el enclave de los estudios filosóficos en el marco de la preparación intelectual para el sacerdocio:

La búsqueda de la Verdad: el hombre no puede sustraerse a la pregunta acerca de la realidad última, que no esté sujeta a la variabilidad del mundo. En nuestro camino histórico no nos conformamos con lo inmediato o lo caduco: aspiramos a proyectarnos, a analizar los acontecimientos, a descubrir lo que nos parece velado e inescrutable y que sin embargo se nos ofrece a nuestro entendimiento. El hombre no puede renunciar a esta pregunta. La filosofía establece un método, una vía para alcanzar esa verdad. A lo largo de la historia, ha sido competencia de la filosofía esta búsqueda que hoy se ve amenazada por el relativismo ya denunciado por Benedicto XVI: «Mientras que el relativismo, es decir, 'dejarse llevar a la deriva por cualquier viento de doctrina', parece ser la única actitud adecuada en los tiempos actuales, se va constituyendo una dictadura del relativismo que no reconoce nada como definitivo y que deja como última medida sólo el propio yo y sus antojos» ${ }^{4}$.

También el conocimiento técnico quiere desplazar cuando no marginar por completo el acceso a la realidad que no siga el criterio cientificista. De esta manera ya no hay verdades últimas, nada tiene valor intrínseco en sí mismo, sino que se convierte en «apropiado, útil, prescindible, rentable...». Todo puesto bajo la mirada inhumana del aprovechamiento o el utilitarismo. El hombre entonces puede ser descartado, sujetarse a manipulaciones 0 experimentos y decidir acerca de su conveniencia. Buscar la Verdad, que es Dios mismo, hace que también en el ser humano sea descubierta la ver-

4. Card. J. Ratzinger, Missa pro eligendo pontifice, 18 de abril de 2015. 
dad propia. La razón como momento constitutivo del acto de fe: Dios se ha dado a conocer al hombre mediante la razón humana. La filosofía ayuda a estructurar la mente de tal manera que posibilita un acto de fe más lúcido. «Es ilusorio pensar que la fe, ante una razón débil, tenga mayor incisividad; al contrario, cae en el grave peligro de ser reducida a mito o superstición. Del mismo modo, una razón que no tenga ante sí una fe adulta no se siente motivada a dirigir la mirada hacia la novedad y radicalidad del ser» ${ }^{5}$. La razón no solamente es necesaria para la fe, sino que es constituyente del acto mismo de fe. La estructura dialógica de la Revelación, Dios que se acerca al hombre y este que responde, reclama también un asentimiento de la razón, una comprensión última del hombre libre que es interpelado, y que necesita comprender para responder. «EI mensaje cristiano se propone siempre en lenguaje humano $y$, por ende, es un repensar la palabra divina dentro de lo humano; no se propone, pues, nunca en su absoluta e incontaminada pureza divina. Ello vale ya para la Sagrada Escritura, porque también ahí se presenta la Palabra de Dios como palabra de hombre, en un lenguaje humano y aceptando sus limitaciones. Una determinada imagen del mundo le imprime su cuño y en ella entran por tanto determinados modos de pensar, de imaginar y de sentir. De este modo la predicación cristiana contiene siempre, aparte del kerygma único que obliga, una parte humana que no puede en manera alguna reclamar semejante obligatoriedad. Síguese que el diálogo con la ciencia humana resultaría siempre necesario por la sencilla razón de que siempre habrá que conocer y deslindar lo puramente humano. Comoquiera que en el kerygma hay siempre algo que en realidad no es kerygma, sino elaboración humana, se impone en cada época la escucha paciente de lo que la humanidad sabe de hecho" ${ }^{6}$. Es obvio que cuanto menos conozco a una persona, menos libre soy para aceptar su amistad o para fiarme de ella. Por el contrario, conocer a alguien y comprender su comportamiento, posibilita en mí una respuesta más auténtica y libre. Junto a esto, la filosofía desarrolla un razonar que hace que comprendido el núcleo de la fe, pueda ser expuesto al hombre de hoy en categorías apropiadas. Reducir la fe a un acto emotivo o sentimental hace que su valor universal quede oscurecido.

La reflexión teológica precisa la reflexión filosófica: en el fondo, ambas disciplinas se interrogan acerca de los problemas fundamentales del hombre, si bien los abordan desde distintas ópticas. Una parte de Dios y de su manifestación al hombre. La otra parte del hombre en su búsqueda por el

5. Juan Pablo II, Fides et ratio, 48.

6. J. Ratzinger, El nuevo pueblo de Dios. Esquemas para una eclesiología, Madrid 1972, 327. 
sentido, que para el creyente es Dios. En este camino de reflexión, ambas disciplinas se encuentran, al igual que Dios y el hombre se han encontrado en el Logos Encarnado. La teología no podría abordarse si no se tuviera un pensar filosófico, una estructura de pensamiento capaz de adentrarse en el Misterio con los presupuestos de la razón humana.

La reflexión filosófica constituye un momento interno permanente (infra-estructura) del pensar teológico. La teología no podrá cumplir las exigencias de una comprensión de la fe hasta el fondo, sino preguntando críticamente, pensando metódicamente y buscando la elaboración sistemática del contenido de la revelación, es decir, haciendo filosofía. Una teología, que pretendiera prescindir de las exigencias de una auténtica reflexión filosófica, sería víctima de una filosofía acrítica y bastarda: de una pseudofilosofía no puede resultar sino una pseudoteología. La reflexión teológica implica, pues, en sí misma la reflexión filosófica ${ }^{7}$.

\section{LOS ESTUDIOS DE TEOLOGÍA}

Finalmente, dedicamos algunas líneas a la presentación de los estudios de teología que en la Ratio ocupan los números 165-175. En consonancia con todo lo expuesto anteriormente por el mismo documento, se persigue una visión unitaria e integral de la teología, que pueda evitar cualquier tipo de fragmentación del conjunto de disciplinas.

En efecto, la tentación de desconectar las materias está siempre presente en un mundo que aboga por una visión fragmentada de la historia y de la misma comprensión del hombre. Ya advertía Juan Pablo II hace 30 años sobre esta fragmentación:

La verdad es una, pero se presenta a nosotros de forma fragmentaria a través de los múltiples canales que nos conducen a su cercanía diferenciada... En cuanto ciencias, la filosofía y la teología son también ellas intentos limitados para percibir la unidad compleja de la verdad. Es sumamente importante intentar, por una parte, la búsqueda de una síntesis vital, cuya nostalgia nos aguijonea, y por otra, evitar cualquier sincretismo irrespetuoso de órdenes de conocimientos y grados de certeza distintos ${ }^{8}$.

Hay también un aspecto interesante en el número que sirve de preámbulo a toda esta sección de los estudios de teológicos, dicho aspecto se aclara con una cita: «En realidad, a través del estudio, sobre todo de la teología,

7. J. Alfaro, «Teología, filosofía y ciencias humanas», en Revelación cristiana, fe y teología, Salamanca 1985, 130.

8. Juan Pablo II, Discurso a los participantes en el Coloquio sobre "Ciencia, filosofía y teología», 5 de septiembre de 1986, 1. 
el futuro sacerdote se adhiere a la Palabra de Dios, crece en su vida espiritual y se dispone a realizar su ministerio pastoral ${ }^{9}$. Si nos interesa esta aseveración acerca de la formación intelectual es porque vincula dos planos esenciales que cohesionan el proceso de formación de los candidatos al sacerdocio: el conocimiento está íntimamente conectado con el crecimiento. Ya en párrafos anteriores abordamos esta idea, pero no está de más repetirla: la formación intelectual no se puede sustraer a la maduración de la persona, como si fuera un ámbito inconexo. Es más bien posibilidad y garantía de un despliegue cada vez mayor y más serio de las capacidades globales de cada uno.

Este capítulo VII de la Ratio que estamos comentando está dedicado por completo a los estudios para la formación sacerdotal. En el apartado relativo a los estudios teológicos la Ratio se detiene a repasar cada una de las áreas propias de la teología, como no podía ser de otra manera. A modo de resumen las mencionaremos:

La Sagrada Escritura es el alma de la teología, como ya expresara el documento conciliar Dei Verbum. Tiene una enriquecedora visión acerca del estudio de la Palabra de Dios, pues no se remite únicamente a la investigación científica de los textos o a la visión utilitarista de los mismos, como justificación de otro tipo de verdades, sino que plantea un estudio complexivo, cito textualmente, «desde la Lectio divina hasta la exégesis»"

Con una visión que excluye el reduccionismo, también la Sagrada Liturgia (Ratio 167,15$)$ es presentada en términos globales y a la vez específicos, abordando sus aspectos teológicos, espirituales, canónicos y pastorales. Este número se cierra con una recomendación más que interesante en nuestros tiempos: separar lo que en la Liturgia es esencial de lo que se ha ido añadiendo con el tiempo. Es bueno que los futuros pastores del Pueblo de Dios no trivialicen en la celebración de los Sagrados Misterios, mucho menos que centren su atención litúrgica o su «ars celebrandi» en formas caducas, inclinaciones de carácter personal o proyección de gustos arqueologistas. La Iglesia, que es sabia, quiere colocarnos en el centro de la acción celebrativa, aunque nosotros queramos dar más importancia a los roperos de la sacristía.

La Dogmática (Ratio 168, 16) tiene un método propio que es conveniente respetar: acceso a los datos positivos contenidos en la Sagrada Escritura, en los Padres y en el Magisterio como desarrollo del Dogma y reflexión sistemática acerca de los mismos. No para repetir mecánicamente las ver-

9. Juan Pablo II, Pastores dabo vobis 51.

10. Ratio 166, que cita a Benedicto XVI en Verbum Domini, 35. 
dades ya conocidas, sino para traducirlas al hombre de hoy que está en búsqueda de la realidad última de sentido. Me extiendo un poco en una cita de Joseph Ratzinger:

[En el Vaticano II] queda superada una forma estrecha de teologizar que pudiera definirse ... como teología de encíclicas... Significa una forma de teología en que la tradición parecía lentamente estrecharse a las últimas manifestaciones del magisterio papal... El concilio...manifestó e impuso también su voluntad de cultivar de nuevo la teología desde la totalidad de las fuentes, de no mirar estas fuentes únicamente en el espejo de la interpretación oficial de los últimos cien años, sino de leerlas y entenderlas en sí mismas; manifestó su voluntad no sólo de escuchar la tradición dentro de la Iglesia católica, sino de pensar y recoger críticamente el desarrollo teológico en las restantes Iglesias y confesiones cristianas, dio finalmente el mandato de escuchar los interrogantes del hombre de hoy como tales, y partiendo de ellos, repensar la teología y, por encima de todo esto, escuchar la realidad, «la cosa misma» y aceptar sus lecciones ${ }^{11}$.

También la Teología Fundamental, que va a las fuentes mismas del pensar teológico, ha de ser presentada desde un espíritu ecuménico y desde un profundo diálogo con el mundo contemporáneo.

La Teología Moral (Ratio 169) quiere ofrecerse a la reflexión teológica desde su íntima conexión con la Sagrada Escritura, de la que brota, para favorecer en el hombre no la observancia de unas normas que en último término lo subyuguen, sino para propiciarle la vida según el Espíritu, vida de libertad de hijos. En estrecha relación a ella se encuentra la Teología Espiritual, especialmente la espiritualidad sacerdotal, como complemento de la Teología Moral.

Con un método propio se presenta la Teología Pastoral (Ratio 170). Pero conviene hacer notar que esta disciplina no es un conglomerado de ocurrencias o iniciativas sin armonización, sino un planteamiento metodológico para estudiar la realidad donde el Evangelio quiere ser sembrado. Con el mismo espíritu se habla de la Misionología (Ratio 171), no solamente desde el clásico aspecto de missio ad gentes, sino también con la forma más o menos reciente de Nueva Evangelización.

La Doctrina Social de la Iglesia (Ratio 172), con el reciente añadido de una reflexión acerca del ecologismo, es ofrecida en el contexto de un anuncio del Evangelio vinculado a la promoción social, la búsqueda de la justicia, los valores de la solidaridad y la salvaguarda de los derechos relacionados con el trabajo.

11. J. Ratzinger, El nuevo pueblo de Dios, 318-319. 
La Historia de la Iglesia (Ratio 173) quiere ser una herramienta útil para la comprensión del caminar del pueblo de Dios, extendido en el tiempo y en el espacio con sus particularidades, atendiendo siempre a la enseñanza que se puede extraer de la experiencia multisecular de la Iglesia.

La visión que se ofrece del Derecho Canónico (Ratio 174) se halla en íntima conexión con el propósito fundamental de este apartado: su vinculación con la misión pastoral que luego el estudiante deberá emprender. En el Derecho se encuentra también una herramienta útil para relacionarlas con la problemática familiar, ejerciendo el bálsamo de la misericordia y orientando toda su utilidad hacia la ley suprema de la Iglesia: la salvación de las almas.

Finalmente, se incluyen las materias que ponen en relación la verdad de nuestra fe con otras formas de comprensión cristiana o simplemente religiosa. Así, el Ecumenismo y la Historia de las religiones (Ratio 175) constituyen una tarea urgente, habida cuenta de la proliferación de confesiones cristianas que se encuentran presentes en nuestra sociedad, reclamando de nosotros una reflexión profunda acerca de los desafíos que presentan a nuestra Iglesia y a nuestra evangelización.

Este breve recorrido nos sitúa en la órbita de una comprensión más adecuada de la organización de la teología en el contexto de la formación de los sacerdotes. En este panorama se entrevén los ejes vertebradores de todo el documento, que hace que la formación intelectual, como toda la formación sacerdotal, sea única, integral, comunitaria y misionera. Querer deslindar la reflexión teológica de estas líneas de trabajo no solamente repercute en una formación disgregada o asentada únicamente en el emotivismo tan frecuentemente ensalzado hoy, sino que también impide que el ser humano pueda encontrarse frente al Misterio y sumergirse desde su propia razón en Él, preguntándose y admirándose, descubriendo y relacionando, aprendiendo y anunciando.

Cito, para concluir, a Benedicto XVI:

La fe cristiana tiene una dimensión racional e intelectual esencial. Sin esta dimensión no sería ella misma. Pablo habla de un «modelo de doctrina», a la que fuimos entregados en el bautismo (Rom 6, 17). Todos conocéis las palabras de san Pedro, consideradas por los teólogos medievales como justificación de una teología racional y elaborada científicamente: «Estad siempre prontos para dar razón (logos) de vuestra esperanza a todo el que os la pidiere» $(1 \mathrm{Pe} 3,15)$. Una de las tareas principales de los años de seminario es capacitaros para dar dichas razones. Os ruego encarecidamente: Estudiad con tesón. Aprovechad los años de estudio. No os arrepentiréis. Es verdad que a veces las materias de estudio parecen muy lejanas de la vida cristiana real y de la atención pastoral. Sin embargo, es un gran error plantear de entrada 
la cuestión en clave pragmática: ¿Me servirá esto para el futuro? ¿Me será de utilidad práctica, pastoral? Desde luego no se trata solamente de aprender las cosas meramente prácticas, sino de conocer y comprender la estructura interna de la fe en su totalidad, de manera que se convierta en una respuesta a las preguntas de los hombres, que aunque aparentemente cambian en cada generación, en el fondo son las mismas ${ }^{12}$.

12. Benedicto XVI, Carta a los seminaristas, 18 de octubre de 2010. 